\title{
AS NOVAS TECNOLOGIAS REPRODUTIVAS: O ESTATUTO DO EMBRIÃO E A NOÇÃO DE PESSOA
}

Tania Salem

\section{Introdução}

Dentre os inúmeros dilemas que vêm emergindo graças à crescente afirmação das tecnologias reprodutivas - em especial, da fertilização in vitro - , destaca-se o referente ao estatuto moral do embrião1. A questão é decerto muito antiga, mas, especialmente nos anos 70 , ela converteu-se em uma importante questão pública em virtude do debate sobre o aborto que eclodiu com vigor sem precedente em alguns países ocidentais. Embutidos aí subjazem dois problemas interligados, diante dos quais os campos em discórdia tiveram (e têm) que, explícita ou implicitamente, se manifestar: de um lado, o estatuto do embrião em si mesmo; de outro, como hierarquizar os "interesses" e "direitos" do embrião (ou do feto) relativamente aos da mulher que o abriga.

Nos anos 80 a discussão sobre o estatuto do embrião volta à cena, porém de forma transfigurada. Em contraste com o verificado na década precedente, o debate tem como pano de fundo uma situação totalmente diversa e, ademais, refere-se a uma entidade inédita possibilitada pela fertilização in vitro: o embrião extracorporal (também nomeado de "préimplantado"). Ou seja, o que está em pauta é o embrião fertilizado e "criado" em laboratório, capaz de sobreviver em estado suspenso de animação (isto é, congelado) por tempo indefinido fora do corpo de uma muIher2. Se é inegável que os debates sobre o embrião in utero e o ex utero suscitam dilemas coincidentes, e podem ter importantes repercussões entre si, é impossível deixar de reconhecer que nos defrontamos também com um cenário e interrogações de fato inusitados. Assim é que, ao lado de questões que dizem respeito ao embrião contido por um corpo feminino, se agregam outras indagações: se, de um ponto de vista técnico, o embrião extracorporal pode ser congelado por tempo indeterminado, qual o limite de tempo socialmente tolerado para sua manutenção nesse esta- 
do? O que fazer com os embriões ditos "excedentes" e com os milhares dos chamados "embriões-órfãos" que não estão sendo reclamados por seus genitores 3 ? É legítimo implantar embriões em um útero após a morte de um dos cônjuges? Como resolver eventuais disputas sobre a sorte de embriões congelados que podem emergir entre os genitores, ou entre estes e o corpo médico? Quem, afinal, tem autoridade para falar em seu nome ou para decidir sobre seu destino? E, mais importante para meu presente propósito: que tipo de manipulações podem ser realizadas em embriões extracorporais? É eticamente admissível criá-los em laboratório visando seu uso exclusivamente para fins de pesquisa?

As duas últimas indagações anunciam desde já que o atual debate sobre o embrião extracorporal é, ao menos em parte, alimentado pela possibilidade técnica, aberta pela fertilização in vitro, de realizar pesquisas com eles. Dentre os inúmeros benefícios daí decorrentes, costuma-se salientar, além do avanço de técnicas relacionadas com a infertilidade, do desenvolvimento de métodos contraceptivos e de um maior entendimento do câncer, também algo que já vem sendo ensaiado nos últimos anos: o diagnóstico pré-implantação. Por intermédio dessa técnica é possível detectar nos embriões doenças genéticas ou cromossômicas severas, resultando daí a opção de descartar (isto é, de não transferir para o útero) aqueles tidos como "defeituosos". Assim, as indicações para a fertilização in vitro - que na década de 80 se restringiam a casais inférteis vêm se ampliando consideravelmente nos últimos anos. M as esses eventuais benefícios não aplacam aqueles que vêem nessa manipulação um atentado contra a vida e a espécie humanas, nem os que nela vislumbram os horrores de um "admirável mundo novo". Discute-se, em suma, se esses procedimentos exploratórios são eticamente aceitáveis ou não; e, em caso de uma resposta afirmativa, pergunta-se quais são seus limites4.

Pode-se dizer que, grosso modo, são três as posições que emergem dos debates. Cada uma delas expressa uma determinada concepção acerca do estatuto do embrião em geral e do extracorporal em particular, e, em consonância, elas anunciam diferentes posturas diante da questão da sua manipulação. Em um dos extremos encontram-se aqueles que, alegando que o embrião é desde sua concepção um ser moral com “direito à vida", se opõem não só a experimentos com ele, como também à sua criação em laboratório. U ma versão menos radical dessa vertente consente com a fertilização in vitro se - e somente se - todos os ovos fertilizados forem transferidos para o útero. No outro pólo, estão os que sustentam não haver nenhuma diferença significativa entre o embrião e outros tecidos humanos; assim sendo, advogam que sua manipulação é legítima e 
que quaisquer limites impostos à pesquisa, além de carecerem de sentido, pecam por comprometer o progresso da ciência. A posição intermediária defende que, embora não tenha o mesmo estatuto de uma criança ou um adulto, o embrião extracorporal é merecedor de respeito e de considerações especiais, tendo em vista seu caráter de "pessoa humana potencial". M as, ao mesmo tempo, insiste-se em que esse respeito não deve ter um sentido absoluto; antes, ele deve ser avaliado em função dos benefícios que podem resultar da pesquisa com embriões para outros seres humanos (Warnock 1985:62-63).

$\mathrm{O}$ dilema moral referente às condições de permissibilidade da pesquisa vem sendo insistentemente traduzido nos termos de quais os atributos que conferem ao embrião o caráter de um ente moral e/ou a partir de que momento ele se afirma enquanto tal. É precisamente a consolidação dessa(s) qualidade(s) e/ou desse instante fundador que estipula o divisor de águas entre a pesquisa eticamente admissível e a inadmissível envolvendo embriões humanos ex utero. Por outro lado, a questão do até quando vem acompanhada de uma outra que concerne às manipulações tidas como moral mente intoleráveis tout court; isto é, que devem ser rejeitadas independentemente do momento em que sejam realizadas 5 .

É evidente, contudo, que subjazem a esse debate temas que extrapolam amplamente o embrião. Pode-se conjecturar que uma análise cautelosa dos experimentos que são - ao menos por ora - terminantemente rechaçados é capaz de revelar aquilo que é encarado como implicando uma transgressão abominável da ordem do mundo e, simultaneamente portanto, qual a ordem sacralizada. Ainda que instigante, o assunto escapa aos propósitos deste artigo, o qual aborda uma outra questão. Sustento que o próprio modo de formular o dilema envolvido na manipulação de embriões evidencia que, em última instância, está-se discutindo a Pessoa: o que significa ser pessoa e quais as qualidades que instalam em um ser humano essa condição. Sob esse ponto de vista, o debate aqui focalizado pode ser analiticamente encarado como um "texto cultural", isto é, como expressivo das representações sociais ocidentais sobre esse tema maior. M as é fato também que - como em uma via de mão dupla - as linhas básicas de argumentação presentes na discussão só adquirem inteligibilidade quando referidas à categoria ocidental de Pessoa: o Indivíduo.

Ainda que no debate em pauta seja bastante corrente a identificação entre "o ponto a partir do qual a vida humana começa a importar em termos morais", "o momento em que o embrião passa a ter 'direitos' e 'interesses'" e "o momento em que o estatuto de pessoa deve ser a ele conferido", observa-se também, por vezes, a tese de que o instante de con- 
solidação de um desses atributos não coincide necessariamente com o dos outros ${ }^{6}$. Não causa surpresa, portanto, que um mesmo ente em certo estágio de desenvolvimento seja, dependendo do seu "observador", designado ora de "Pessoa", ora de "não-Pessoa", ora de "pré-Pessoa" ou, ainda, de "potencial de Pessoa". Contudo, argumento que a falta de consenso quanto ao modo de responder ao problema do que é ser Pessoa e de seu momento fundador é contrabalançada pela presença de supostos culturais compartilhados, e que é exatamente com base na análise dos mesmos que é possível avançar nas representações de Pessoa aí embutidas. Por outro lado, tensões, contradições e paradoxos são fenômenos endêmicos ao domínio do ideológico, e eles imiscuem-se igualmente na nossa categoria axial de Indivíduo (Dumont 1977). No debate sobre o embrião, as tensões que cercam a noção ocidental de indivíduo também se manifestam. Com efeito, conforme desenvolvido no tópico final deste artigo, a discussão dos critérios que erigem este ser à condição de Pessoa descortina a presença, ainda que subordinada, de valores ou vetores que são, em princípio, antitéticos ao de Indivíduo.

Enquanto o material etnográfico em que me apóio apresenta como interrogação central "quando" o embrião se afirma como Pessoa, o ponto de vista aqui privilegiado desloca o problema para "quem" ou, mais precisamente, "como" se fala dele. Explorar de que maneira a noção de indivíduo se imiscui no nosso modo de conceber o embrião permite, simultaneamente, desvelar aquilo que é ocultado nesse discurso. Nele, conforme argumentado adiante, as relações sociais, em geral, e as de parentesco, em particular, são tornadas invisíveis ou, na melhor das hipóteses, despontam de modo subordinado ou contingencial.

Essa inflexão no modo de conduzir a questão - de "quando" se instala a Pessoa para "como" se fala dela - coloca este artigo em sintonia com outros trabalhos antropológicos, mais ou menos recentes, que examinam de que maneira categorias e/ou estereótipos culturais informam e modelam nossas concepções de mundo. As representações letradas ou científicas - que constituem o foco prioritário deste artigo - não são exceções à regra. O trabalho de Emily M artin (1992) sobre como o conceito de reprodução biológica está permeado por estereótipos culturais de gênero e o de Emily Keller (1995) sobre o impacto de normas culturais e metáforas no desenvolvimento das ciências naturais e na condução da pesquisa biológica são apenas ilustrativos do intuito de desvelar a construção social de fatos naturais. Outros trabal hos que adotam essa perspectiva - inclusive os mais diretamente relacionados com as "novas" tecnologias reprodutivas e o tema do parentesco - são comentados ao longo deste artigo. 
Cerco o atual debate sobre o embrião extracorporal utilizando como material uma documentação relativamente heterogênea. Ela abarca desde artigos mais propriamente acadêmicos que se posicionam diante do tema do estatuto moral do embrião até legislações internacionais recentemente promulgadas na área de reprodução assistida. Examino ainda relatórios produzidos por comitês europeus e americanos criados para formular sugestões para políticas públicas ou legislações futuras. Confiro um mesmo estatuto às leis e às recomendações para elas: para os propósitos aqui estipulados essa simplificação não parece acarretar conseqüências mais sérias.

Uma última observação: é inegável que a categoria de "Ocidente" ou, como preferem alguns, a "euro-americana" (Strathern 1992; Rapp 1995:84) - tal como a de "individualismo" - é, sob certo ponto de vista, muito generalizante. À medida que nos aproximamos de níveis mais etnográficos de análise, inevitavelmente despontam não só diferenças culturais no interior de cada país, mas também entre eles. Assim, por exemplo, os distintos modos como os Estados Unidos, Inglaterra e França vêm legislando sobre as tecnologias reprodutivas atestam diferenças nacionais e culturais não desprezíveis, apontando, inclusive, para diferentes modalidades de concepção de Pessoa. Por outro lado, como procuro argumentar tomando como foco as atuais discussões sobre o embrião, há também incontestáveis similaridades que se sobrepõem às eventuais diferenças nacionais. Não há, aí, nenhuma inconsistência lógica ou contradição: afinal, conforme sublinhado por Evans-Pritchard, sabe-se da dificuldade, senão impossibilidade, de substancializar categorias sociológicas e ideológicas. Em outras palavras, as similaridades ou dissimilaridades entre unidades sociológicas ou configurações ideológicas prendem-se, em última instância, ao ponto de vista (mais generalizante ou mais particularizante) el eito pelo investigador. E, repito, para os propósitos e para o ponto de vista aqui eleito, as diferenças culturais nacionais são desprezíveis. Elas podem, de modo frutífero e interessante, ser maximizadas; mas esta é uma questão para outro artigo.

\section{A instauração da Pessoa: as divergências nos debates}

A disparidade de respostas quanto ao momento a partir do qual o embrião passa a importar em termos morais nada mais é do que uma decorrência da falta de consenso com respeito aos critérios que instauram a condição de Pessoa. Deixemos de lado, por ora, o embrião extracorporal. Diante 
dessa indagação mais geral, um inegável privilégio é conferido a referências de cunho biológico: a noção de "viabilidade" - ou seja, a capacidade de ter uma existência independente do útero materno (estabelecida, grosso modo, entre a 24a e a 26a semana de gestação) - é largamente utilizada. Ela informa algumas das legislações vigentes sobre o aborto (como, por exemplo, a americana); isto é, a viabilidade estipula o limite a partir do qual os "direitos" da mulher sobre seu corpo são restringidos na mesma medida que os direitos do "seu" feto são afirmados. O Comitê Nacional de Ética Francês também recorre a essa noção como estabelecendo o marco distintivo entre a "pessoa humana potencial" e a "pessoa humana tout court" (Ladrière 1986:96). A formação do cérebro, a capacidade neurológica de sentir dor ou prazer são outros dos inúmeros eventos cruciais que disputam prevalência na arena dos debates.

Outros autores, pelo contrário, reclamam a precedência de indicadores morais: "a viabilidade não demarca a condição de pessoa porque ainda falta ao feto viável a habilidade da razão e a capacidade de fazer escoIhas" (Robertson 1994:51, ênfase minha)7. Questionando a tese de que todos os seres humanos têm direito à vida, Kuhse e Singer propõem que somente o têm aqueles que "possuem qualidades mentais que outros seres vivos não possuem [como] autoconsciência, razão, senso moral, autonomia" (1993:70, ênfase minha). Tal como esses autores, J ohn Harris insiste que é a "posse" (sic) de uma característica moral particular - a saber, "a capacidade de valorizar sua própria existência" (1993:68) - que promove um ente humano à condição de Pessoa. De acordo com o filósofo, esse atributo não só distingue "pessoas" de "não-pessoas" (das quais fetos e embriões seriam apenas exemplos), como também justifica por que privar as últimas de existência não pode causar-Ihes mal: "a morte não pode destituí-las de algo que são incapazes de valorizar" (Harris 1993:68).

Tendo em vista essa disparidade de critérios não causa surpresa que as respostas fornecidas à questão do momento em que se instala a condição de Pessoa variem desde a fecundação até algum ponto (indeterminado) depois do nascimento ${ }^{8}$, e que, entre esses dois extremos, se anunciem inúmeros outros cortes temporais intermediários.

Aos indicadores até aqui mencionados se somam outros que, embora dizendo respeito à vida embrionária em geral, assumem especial relevância no contexto do debate sobre o embrião extracorporal. Pode-se mesmo dizer que a estipulação desses marcos foi instigada pela existência desse novo ente. Ou seja, é precisamente a eventualidade de que ele não venha a ser transferido para um corpo feminino em virtude de uma decisão humana, e ainda, sua afirmação como objeto de pesquisa, que incitam 
a determinar o estatuto do embrião antes de sua implantação no útero. A questão carece de sentido quando o embrião se encontra inserido em um corpo feminino, seja por meio da fecundação por via natural, seja mesmo graças à sua transferência para aí após ter sido fertilizado in vitro. A eventualidade de que ele não chegue, nessas circunstâncias, a se fixar no útero, não desponta como implicando dilemas éticos: o fato é simplesmente interpretado como um desígnio da natureza, como um aspecto da esterilidade feminina ou como o fracasso de uma terapêutica. Portanto, a questão do estatuto do embrião extracorporal ou "pré-implantado" é efetivamente inédita: incide sobre um novo ente (na verdade, um "entre") e nela embute-se, entre outros dilemas, o do "até quando" é social e moralmente tolerável mantê-lo em laboratório para fins de experimentos científicos.

Entre os comitês de ética ou países que vêm recomendando ou legislando, embora sempre com reservas, em favor de pesquisas com embriões extracorporais, é possível observar a afirmação de um acordo quanto ao tempo-limite tolerado para essas manipulações: elas não podem ultrapassar os quatorze dias após sua fecundação. Algumas legislações determinam inclusive que qualquer pesquisa realizada para além desse tempo é considerada um crime passível de punição legal 9 .

Ora, o que é este ser até os quatorze dias de vida dentro de um corpo feminino que autoriza sua manipulação quando fora dele? Comecemos pelo que ele não é: nem Pessoa, nem - de acordo com alguns "potencial de pessoa", nem mesmo embrião. De fato, o ente existente até os quatorze dias pós-fecundação foi sintomaticamente rebatizado, em meados dos anos 80 , de "pré-embrião". Não resta dúvida de que essa renomeação está atrelada, em grande parte, ao intuito de aplacar resistências às pesquisas com embriões, e o dilema moral concernente é, nesse contexto, reduzido a um mero problema semântico10. Seja como for, vale examinar as características distintivas do "pré-embrião" (ou, inversamente, o que lhe "falta") que autorizam considerá-lo como um "outro". É possível cercar essa questão examinando os argumentos que são comumente expostos para justificar o limite dos "quatorze dias". O corte condensa diferentes critérios e/ou justificativas - todos eles ancorados em processos de maturação biológica que afetam o embrião.

Alega-se, em primeiro lugar, que até os quatorze dias de vida o embrião é incapaz de sentir dor ou prazer. $\mathrm{Na}$ verdade, acredita-se que essa capacidade se instala apenas mais tarde - por volta do $22 \circ$ ou 23 o dia -, quando se inicia a formação do sistema nervoso central. Nesse sentido, os quatorze dias não chegam a constituir um marco; mas a garantia da insensibilidade do embrião até esse momento se afirma como cri- 
tério importante para estipular o tempo que ele pode permanecer vivo in vitro e/ou para a realização de pesquisas: "[até esse momento] o embrião não pode ser maleficiado - em um sentido moralmente relevante - por nada que façamos com ele" (Kuhse e Singer 1993:73).

A "altíssima taxa de mortalidade natural" verificada em embriões humanos in vivo nessa fase - decorrente da freqüente dificuldade de sua fixação no útero - desponta como a segunda justificativa em prol dos quatorze dias, posto que essa data assinala o fim do ciclo "natural" de implantação (cf., por exemplo, Warnock 1985:60 e NIH 1994:2). Podese presumir que $o$ argumento tenha como alvo críticas correntes de que $o$ homem, por meio do uso e abuso das tecnologias reprodutivas, estaria intervindo desmesurada e indevidamente na natureza ou em processos naturais. M as a resposta assume uma forma no mínimo curiosa: ao decidir pela não implantação de embriões no útero para fins de pesquisa - e pelo seu posterior descarte11 - estar-se-ia tão-somente "respeitando", senão imitando, as leis da natureza...

Os argumentos que se seguem sobressaem em importância aos acima vistos. O terceiro - aliás, o mais citado - enfatiza que entre o 14 e o 15o dia após a fertilização se anuncia no embrião, tanto no in utero quanto no ex utero, a formação da "linha primitiva" (primitive streak) da qual se origina a coluna vertebral. Insiste-se que a importância desse evento deriva do fato de ele demarcar o último estágio no qual pode ocorrer a duplicação espontânea do embrião. Isto é, até esse momento as células que compõem o embrião (ou, caso se prefira, o pré-embrião) podem se dividir em grupos de células idênticas, dando origem a dois ou mais indivíduos idênticos. Decorre daí a conclusão, repetida ad nauseam, de que até o despontar da linha primitiva "o ovo fertilizado não pode ser considerado como um novo indivíduo porque ele pode vir a ser dois indivíduos" (Harris 1990:68, ênfases minhas). É precisamente a "ausência de um desenvolvimento individual do embrião" até o 14o dia que leva o Comitê patrocinado pelo National Institutes of Health (EUA) a defender a tese de que pesquisas com ele devem ser permitidas, ainda que com algumas restrições, até essa data (NIH 1994:2; ver também Warnock 1985:68). O marco biológico em pauta estipula, em suma, a passagem do estágio pré-embrionário para o embrionário propriamente dito e anuncia um embrião (ou uma identidade) único e singular ${ }^{12}$.

O fim do estágio de implantação de um embrião inserido em um corpo feminino é o outro critério invocado para determinar o limite de tempo para a manipulação de embriões extracorporais. A fixação no útero é entendida como um processo que, iniciado por volta do 6 o dia após a fer- 
tilização, completa-se entre o 12o e o 13 dia de vida intra-uterina. Ainda que alguns advoguem que o tempo limite para a manipulação de embriões deveria ter como ponto de referência o princípio do processo de implantação, é o seu término que vem se afirmando como ponto de demarcação. A justificativa para tal encontra-se sumariada nas palavras do comitê Warnock: "a não ser que o embrião se implante em um ambiente humano uterino [sic], ele não tem nenhum potencial para desenvolverse" (1985:62). Por conseguinte, conclui Warnock, o pré-embrião humano "não pode ser pensado como pessoa, e nem mesmo como potencial de pessoa" (1985:62, ênfases minhas), decorrendo daí a legitimidade de mantê-lo vivo em laboratório para fins de pesquisa.

\section{O embrião como Indivíduo: a convergência nos debates}

Como se vê, vinga uma absoluta falta de consenso quanto às respostas fornecidas ao tema do estatuto do embrião. Por outro lado, um exame atento dos critérios acima comentados - concernentes seja ao embrião em geral, seja ao pré-implantado em particular - leva à sugestão de que, para além das discordâncias com respeito ao evento crucial que funda a Pessoa (ou a "pessoa potencial"), há inegáveis premissas culturais comuns entre elas. E, como já propus, é exatamente com base na sua análise que é possível avançar nas representações de Pessoa embutidas no debate.

A primeira assenta-se no que já foi designado de uma "concepção gradual de pessoa" (Luker 1985:180). De fato, exceção feita aos que estabelecem o momento da concepção como o marco que instaura a pessoa com "direitos" e "interesses" decorrentes, todas as demais posições encaram a vida humana como um continuum no qual o indivíduo emerge gradualmente ${ }^{13}$. Detecta-se, nesse sentido, uma tensão entre, de um lado, o reconhecimento de que a constituição do sujeito é um processo evolutivo inquebrantável e, de outro, a tentativa de identificar um evento crucial a partir do qual nasce, de fato, a pessoa. Conforme já salientado, a idéia de um "ponto inicial" constitui parte do esforço para estabelecer limites e proibições concernentes ao que é eticamente aceitável fazer com embriões ou fetos - embora não só com eles.

O segundo suposto compartilhado - e que nos interessa mais de perto - diz respeito ao modo de conceber os critérios que fundam a Pessoa. Ainda que a determinação das características instauradoras varie consideravelmente, pode-se observar que quase todas confluem para o pressuposto de que é a "posse" de certas qualidades ou marcos distinti- 
vos que promove o embrião a essa condição. Como vimos, são privilegiados atributos ora biológicos, ora morais. Mas, para além de suas diferenças, há uma coincidência fundamental entre eles: a referência básica diz respeito, em ambos os casos, a uma realidade inerente ao próprio embrião. A idéia importa justamente porque denota que a Pessoa é concebida como um domínio autocontido, da mesma forma que ela é valorada e definida em termos auto-referidos: sua identidade vem de dentro e nela própria está contido, de forma potencial, o seu devir.

Essas considerações autorizam o argumento de que a categoria central que informa o debate sobre o embrião e esclarece a noção de Pessoa aí subjacente é a de Indivíduo. Arrisco mesmo a dizer que, para além das discordâncias acerca de seu estatuto como Pessoa, "potencial de pessoa", ou "pré-pessoa", o embrião é (concebido como) um indivíduo. A identificação proposta é inegavelmente peculiar na medida em que, caso se privilegiem critérios morais, este ente está despossuído de características fundamentais como "razão", "autonomia", "capacidade de escolha" e outros atributos capitais atrelados à noção de Indivíduo-valor. Ainda assim, persistem ao menos duas representações basilares ao ideário individualista: em primeiro lugar, a de que o indivíduo existe e se afirma independentemente das relações sociais nas quais ele está imerso; em segundo, sua identificação como um ser único, singular e irredutível.

Examinemos a primeira dessas premissas. A análise do debate sobre o embrião e dos critérios aí invocados é reveladora do privilégio conferido a uma forma não relacional de constituição da Pessoa. Sendo inteligível em seus próprios termos, o embrião resulta ser entendido como um ente a-social ou pré-social, isto é, como logicamente anterior às relações sociais ${ }^{14}$. No debate em pauta, essa forma de representação se anuncia, e tem sua legitimidade assentada, no recurso à linguagem e a critérios supostamente neutros, imparciais e objetivos - da biologia. É a ordem da Natureza - expressa no "fato natural" da "Iinha primitiva" - que provê a base e o fundamento da Pessoa. Pode-se, por conseguinte, falar em uma "biologização" da identidade. A esta inclinação está associada a idéia de que a Pessoa - tanto no plano de sua formação quanto no de seu devir - é determinada antes pela (sua própria) "natureza” do que propriamente pela "cultura".

A emergência e definição de pessoa em termos estritamente biológicos acompanha a posição proeminente que a definição de parentesco euro-americana confere aos fatos naturais (Schneider 1968)15. M as enquanto a noção de "sangue", por exemplo, é um operador simbólico que conecta sujeitos (os parentes consangüíneos), a ênfase em um fato natu- 
ral da embriologia enquanto fundamento da Pessoa ("a linha primitiva") desconecta e oculta relações. Com efeito, a percepção do embrião como indivíduo torna invisível algo que o constitui: não só as relações sociais em geral como também as de parentesco em particular.

A individualização do embrião é tão totalizadora que até a figura da mãe é eclipsada. Autoras feministas vêm salientando que um dos efeitos sociais mais significativos das tecnologias de reprodução assistida sobretudo da fertilização in vitro - é o obscurecimento da gestante na cena do nascimento de uma criança. Conforme sublinhado por Stanworth (1987), a expressão "bebê de proveta" evoca a estranha imagem de um feto que cresce e se desenvolve independentemente de um corpo feminino. Ao analisar as imagens e o imaginário recente sobre o feto, Petchesky (1987) destaca que ele vem sendo distorcidamente apresentado como uma entidade "desconectada", "solitária", "autônoma", ao passo que a mulher aparece como "periférica", quando não "ausente".

Os trabal hos citados referem-se ao embrião (ou feto) inserido em um corpo feminino. De outro lado, porém, deve-se reconhecer que circunstâncias que envolvem a fertilização in vitro impõem a confrontação com uma situação inédita: um embrião não é mais necessariamente concebido em um corpo feminino e pode, sob certas condições, viver fora dele e, portanto, independentemente dele.

Poder-se-ia, nesse sentido, argumentar que o fato de o embrião dito pré-implantado se encontrar efetivamente destacado do corpo feminino incita ainda mais sua percepção como uma entidade singularizada, descontextualizada e passível de ser depreendida em seus próprios termos. Em contraste com a situação do aborto, por exemplo, o embrião não está contido em um(a) "outro(a)" - de um "outro" que, proclamando o direito sobre o "seu" corpo, pode alegar que dispõe do direito de decidir sobre o destino do "seu" embrião. E, ao esvaziar o caráter prioritário que a mulher cumpre nessa cena, não só se evita a espinhosa questão - tão pregnante nas discussões sobre o aborto - de como hierarquizar os "interesses" e "direitos" desses dois seres, como também, e sobretudo, oculta-se a idéia de uma "relação". É precisamente esse novo cenário que pode, à primeira vista, conferir sentido à tentativa de determinar o estatuto do embrião extracorporal considerando-o apenas em termos auto-referenciados.

Por outro lado, é inegável que conceber o embrião extracorporal como desvinculado de uma teia de relações sociais consiste em uma "ilusão" (no sentido dumonsiano) ou em uma distorção. Deve-se considerar que, ao mesmo tempo que o embrião está sendo fisicamente desatrelado do corpo feminino - e talvez justamente por isso - , ele está, de um pon- 
to de vista social, sendo imerso em uma rede social muito mais complexa que outrora. Com efeito, médicos, biólogos, e em alguns casos doadores de gametas - que hoje se encontram diretamente envolvidos na própria concepção do embrião - , freqüentemente, disputam entre si a prevalência para falar em seu nome (N ovaes e Salem 1995). Longe, portanto, de "faltar" ao embrião um contexto, ele encontra-se - como que em consonância com seu estado suspenso de animação - em um espaço de limbo caracterizado, talvez, por um "excesso" de relações.

Voltemo-nos agora para uma outra premissa cara ao ideário individualista - a saber, de que o indivíduo é um ser único e irredutível ${ }^{16}$. No debate sobre o embrião extracorporal essa representação se anuncia quando se estipula que ele só acede ao estatuto de ser moral quando se afirma a certeza de que ele não é, nem pode vir a ser, outro a não ser si mesmo. Assim é que enquanto dotado da capacidade de se cindir em dois (ou mais), o embrião é "rebaixado" à condição de "pré-embrião", "matéria molecular", "mero agregado de células" ou, ainda, à de "não-indivíduo" 17. Visto sob outro ângulo, a identidade exclui por definição a alteridade, e um outro indivíduo é também um "outro" do indivíduo. Para ser promovido ao estatuto de ser moral ou de Pessoa, ele deve ingressar em um estado no qual sua identidade está fixada ou congelada - em um ser que, apesar ou para além de movimentos ou transformações, é sempre único, idêntico a si mesmo e, nesse sentido específico, imutável ${ }^{18}$.

M as o próprio debate acerca do embrião extracorporal permite relativizar esse modo de representação. Basta, por exemplo, invocar a recente categoria de "pré-embrião" : ela, necessariamente, subverte o que se entende por "embrião" e, por conseguinte, é ilustrativa de que as identidades sociais não são fixas nem vêm "de dentro" do próprio sujeito: a intermediação do outro é, aí, fundamental.

Tomemos um outro exemplo. Luker comenta que no princípio do século XIX a tradição anglo-americana tolerava o aborto até o quickening - ou seja, até o feto revelar-se através de movimentos no útero (1985:14-15). Esse critério demarcatório é indicativo de quanto o acesso que se tem a ele (ou ao embrião) - expresso, no caso, com base no "sentir" da gestante - é fundamental para determinar o momento a partir do qual eles passam a "importar em termos morais". Como não poderia deixar de ser, as crescentes formas de acesso médico ao embrião - das quais a fertilização in vitro é o exemplo recente mais bem-sucedido - necessariamente informam e alteram as representações sobre ele e/ou sobre o que Ihe promove à condição de Pessoa. Assim é que sua crescente pal pabilidade e visibilidade, bem como a antecipação gradativa do patamar de 
viabilidade do feto, vêm fornecendo munição para que grupos em diferentes países pressionem no sentido de revogar as legislações que autorizam o aborto - ou, ao menos, de limitar o tempo em que a prática encontra respaldo legal.

Não se trata de limitar o alcance dessas considerações a embriões, fetos ou crianças. O sujeito - qualquer sujeito - pressupõe o pólo da alteridade para se definir e, nessa medida, só se "existe" em relação (Salem 1992).

Em suma, parece plausível sugerir que a conjugação paradoxal entre, de um lado, estar o embrião extracorporal imerso em uma rede mais complexa de protagonistas e, de outro, a insistência em obscurecer as relações sociais e familiares que o envolvem pode ser creditada à nossa inclinação a identificar a Pessoa (no caso, o embrião) como um Indivíduo. É ainda esta mesma disposição que pode elucidar a tentativa de substantivar a identidade do embrião, privilegiando a questão do quando ele se afirma como Pessoa.

\section{As contratendências}

O fato de o Indivíduo afirmar-se como valor moral central no sistema simbólico ocidental, e de informar o modo de abordar o embrião, não elimina a presença de contradições e conflitos no plano das representações. Tensões e paradoxos são constitutivos ao domínio do ideológico e essas qualidades despontam igualmente nas discussões sobre o estatuto do embrião.

Voltemo-nos para o pré-embrião contido por um corpo feminino. Ainda que explícita e insistentemente designado como um "não-indivíduo", ele retém paradoxalmente atributos do Indivíduo-valor. Dentre as várias metáforas a ele associadas, importa aqui salientar a que o identifica com uma "entidade livre e flutuante" 19. A imagem ressalta que, até o instante em que o embrião se fixa no útero, ele "vagueia" solto - primeiro no tubo falopiano e depois na própria cavidade uterina. A qualificação de "livre" - tão cara ao ideário individualista - assume, quando aplicada ao préembrião, um sentido particular: de um lado, ela sugere uma espécie de "irresolução" quanto a se atar ou não. De outro, o atributo de "liberdade" indica que, embora englobado por um corpo feminino, o embrião préimplantado não está ainda contido; ou seja, não está ainda nem refreado, nem submetido, nem relacionado ao útero. Em outras palavras, o que mais precisamente define a "entidade livre e flutuante" é o fato de faltar-Ihe um vínculo. Ora, são precisamente os atributos de auto-referenciamento e 
de liberdade que, entre outros, qualificam o Indivíduo-valor, mas são eles também que fazem do "pré-embrião" um "outro" da pessoa.

Em outras palavras, a contratendência ao lugar central que a noção de indivíduo (e o valor aí alocado) desempenha no debate sobre o embrião é também anunciada nas justificativas que fundamentam o argumento em prol dos "quatorze dias". Se é fato que esse marco condensa o coroamento de processos biológicos "internos" que afetam o embrião, desponta também um (único) critério que sugere relacionalidade: o fenômeno de sua implantação no útero. Embora com presença mais tímida nos debates relativamente ao argumento da "linha primitiva", o marco da nidação do ovo no útero promove o embrião ao estatuto de, no mínimo, "potencial de pessoa"; distingue-o do "pré-embrião" (ou da "matéria molecular") e também é ele, e não a concepção, que estabelece o início da gestação propriamente dita. A o fixar-se aí, o embrião é visto como "perdendo a liberdade" e passando ao estado de "vinculado e dependente" (Ladrière 1986:96, ênfases minhas). São essas qualidades - dentre outras - que estão simbolizadas no marco dos "quatorze dias". Ora, é a partir daí - e somente a partir daí - que o embrião adquire, de fato, direito à proteção, expresso na proibição de mantê-lo vivo em laboratório e/ou de ser objeto de pesquisa.

À guisa de conclusão: o pré-embrião, embora designado de “nãoindivíduo", é, sob um ponto de vista antropológico, a perfeita expressão - ou talvez a caricatura - dos nossos valores sociais. Quando no debate se reconhece que sem implantação - e tudo que ela simboliza em termos de "relação", "vínculo" e "dependência" - o “embrião não tem potencial algum para se desenvolver" (Warnock 1985:62), há como que uma inversão de sinais: o Indivíduo-valor é desqualificado e destronado em prol do reconhecimento de que só existimos como Pessoas.

Recebido em 18 de março de 1996

Reapresentado em 7 de outubro de 1996

A provado em 18 de novembro de 1996

Tania Salem é doutora em Antropologia Social pelo Programa de Pós-Graduação em Antropologia Social (PPGAS) do Museu Nacional/UFRJ e professora licenciada do Instituto de M edicina Social/UERJ . Suas principais publicações versam sobre relações familiares e sobre a questão do individualismo. Atualmente pesquisa temas relacionados às novas tecnologias reprodutivas nos EUA. E-mail: TSalem1428@aol.com. 


\section{Notas}

1 A definição do termo "embrião", bem como o momento em que ele passa a ser entendido como feto, é muito variável. De acordo com o Comitê Nacional de Ética francês, por exemplo, a designação recobre todas as etapas do desenvolvimento que vai da fecundação do ovo até a 25a semana da gravidez, momento em que o ser em gestação é capaz de sobreviver fora do útero materno. Esta posição não é, contudo, dominante; de modo mais usual, admite-se que a fase embrionária se inicia com o encontro do ovo com o esperma e se estende até as oito primeiras semanas de gestação (cf., por exemplo, Warnock 1985:5). Entretanto, em meados dos anos 80 - por razões expostas adiante - , convencionou-se alterar o limite temporal inferior da vida embrionária: o embrião propriamente dito é visto como afirmando-se apenas na 2a semana após a fertilização, e o ente existente até esse momento é (re)designado de "pré-embrião".

2 Simone Novaes e eu já tivemos oportunidade de examinar os efeitos sociais derivados do deslocamento da concepção que, do corpo feminino, dirigese para o laboratório (N ovaes e Salem 1995).

3 Robertson (1994:109) salienta que, em 1990, as clínicas americanas especializadas em fertilização in vitro já abrigavam 23.865 embriões congelados em suas dependências. Ainda que o autor não indique o número de "órfãos" desse total, pode-se supor, com base em estatísticas de outros países, que ele não seja desprezível.

4 Se é incontestável que a peculiaridade da fertilização in vitro reside na externalização dos primeiros estágios da vida humana, permitindo sua observação e manipulação, é fato também que, sob certo ponto de vista, tais possibilidades não são tão novas assim. A rigor, elas já se afirmam em situações nas quais o embrião ou o feto se localizam no útero. Técnicas recentes - como a amniocentese, ultra-sonografia e a cirurgia fetal - vêm instigando a percepção médica desses seres como "segundo paciente" para monitoração e, eventualmente, terapia (Gallagher 1987; Petchesky 1987; Rothman 1987; Aziza-Shuster 1988; Price 1990; Fellous 1991). Não obstante, o fato de a fertilização in vitro ter possibilitado a existência do embrião fora do corpo de uma mulher estipula uma diferença qualitativa fundamental entre as duas situações, impondo também problemas éticos não necessariamente coincidentes (ver, a respeito, N ovaes e Salem 1995).

5 A título de ilustração, a lei inglesa que contempla, entre outros assuntos, a pesquisa com embriões (Human Fertilisation and Embryology Act [HFEA], de 1990) veta a clonagem, a transferência de embriões humanos para o corpo de animais, bem como a de embriões de outras espécies para um útero humano (para o desenvolvimento dessas questões e exceções à regra, ver M organ e Lee 1991: 82). 
6 Por exemplo, alega-se por vezes que um ente humano passa a importar em termos morais e a ter "interesses" e "direitos" antes de se afirmar como Pessoa no sentido pleno do termo (Robertson 1994:53). Outros autores preferem, inclusive, privilegiar a questão de "quando o embrião passa a importar em termos morais", evitando a de "quando" ou "o que" instaura nele a condição de Pessoa. Esta é, por exemplo, a posição advogada por M ary Warnock (apud Harris 1990:66). A filósofa encabeçou o renomado Comitê Warnock estabelecido pelo governo britânico em 1982 para formular sugestões para a elaboração de políticas públicas concernentes às tecnologias reprodutivas. Suas recomendações fundamentam a atual legislação britânica na área promulgada em 1990.

7 Deve-se salientar, contudo, que a distinção entre critérios biológicos e morais é freqüentemente imprecisa. A noção de "viabilidade", por exemplo, embora assinalada como de cunho biológico, apresenta uma conotação moral insofismável: é visto como possuindo "direitos" e "interesses" próprios, o feto que dispõe da capacidade de "individualizar-se" da mãe. Inversamente, muitas das colocações expressas no debate evidenciam que os critérios ditos morais são vistos como fundamentados no desenvolvimento biológico: “um embrião não pode ser uma pessoa nem mesmo um sujeito moral com interesses e direitos tendo em vista seu precário desenvolvimento biológico" (Robertson 1994:51).

8 Ao especular sobre "os critérios de Pessoa", Harris (1993:57 e 59) propõe que "o nascimento não tem nenhum significado especial enquanto demarcador do surgimento de uma pessoa [...] o indivíduo só se torna pessoa em algum momento significativo após seu nascimento".

9 O corte dos "quatorze dias" foi anunciado pela primeira vez, ao que me consta, em 1985, pelo Comitê Warnock (ver nota 6). O marco foi subseqüentemente adotado não só pela legislação britânica (HFEA) como também pelas australiana, canadense e sueca (para um quadro comparativo internacional a respeito das regulamentações de pesquisas com embriões até 1990, ver M organ e Lee 1991:8687). O limite dos "quatorze dias" aparece, ainda, no relatório produzido pela comissão do National Institutes of Health/Human Embryo Research Panel (NIH 1994) criada pelo governo americano para recomendar pesquisas que, envolvendo embriões extracorporais, fossem consideradas aceitáveis para receber financiamento do governo federal. Pretendia-se, assim, reverter o veto a esses financiamentos que vingou por dezoito anos, durante os governos Bush e Reagan, por pressão dos grupos "pró-vida”. A recente legislação francesa relativa ao respeito ao corpo humano promulgada em 1994 - e que contempla questões relacionadas com as tecnologias reprodutivas - é evasiva quanto ao assunto: proíbe a criação de embriões em laboratório para fins exclusivos de pesquisa, e sem vetar manipulações, é silenciosa quanto ao limite de tempo em que elas podem ser realizadas.

10 É exatamente isso que propala, por exemplo, Dawson - uma defensora radical dos experimentos com embriões. Convencida de que um dos problemas inerentes ao debate é de "terminologia" (sic), a geneticista argumenta que a designação de "pré-embrião", introduzida pela primeira vez por um dos mem- 
bros do Comitê Warnock, "elimina a confusão contida no termo embrião" e permite demarcar mais facilmente o que deve ser permitido e o que deve ser proibido em termos de pesquisa (Dawson 1993:14).

11 Legislações atualmente vigentes e/ou recomendações de comitês de ética estipulam que, após serem manipulados, os embriões não podem ser transferidos para o útero de uma mulher. Mas, de um modo geral, eles são destruídos no próprio decorrer da pesquisa.

12 Essa mesma idéia ressurge no contexto da alegação de que, até por volta do 9o dia após a fertilização, o pré-embrião retém a qualidade de ser “pluripotencial". Ou seja, o ovo fecundado carece de especialização: não há meios de identificar quais as células que resultarão na placenta, nas membranas ou no embrião (ou embriões) propriamente dito(s). Reitera-se, assim, a tese de que, do fato de essas células deterem a "potencialidade de tornar-se um ou mais indivíduos diferentes, o embrião humano não é [ainda] um indivíduo particular" (Kuhse e Singer 1993:67; Robertson 1994:251, nota 13).

13 De acordo com alguns, esse movimento não é necessariamente incremental. Harris, por exemplo, insiste em que quando um ser humano perde certas qualidades - basicamente, a de valorar sua própria existência - " ele deixa de ser uma pessoa" (1993:69).

14 M arylin Strathern já desenvolveu hipóteses similares (1992: esp. Parte I, cap. 1).

15 Em vários de seus escritos - ver, por exemplo, A fter N ature (1992a) — Strathern sugere a necessidade de rever as teses já clássicas de Schneider. A autora propõe que as novas tecnologias reprodutivas estariam alterando, de modo drástico e irreversível, nossas representações posto que, mais do que dando uma "assistência" à natureza, elas estariam promovendo uma radical interferência no fato natural. Isto é, mais do que "culturalmente reconstruído", esse domínio estaria sendo "fisicamente redesenhado". Em virtude disso, sustenta Strathern, a "natureza" vem perdendo o caráter de fundamento axiomático para as relações de parentesco: nada mais é evidente, nem mesmo a definição de maternidade. Em um outro trabalho, em que tomo como objeto o princípio do anonimato na inseminação artificial com doador (IAD), argumento que a "desautorização (social) da natureza" é apenas um lado da moeda. Insisto que são as representações biológicas (ou a crença em uma força irresistível da natureza) que subjazem, e conferem inteligibilidade, aos dispositivos de ocultação da identidade do doador (cf. Salem 1995: esp. 62-66).

${ }^{16}$ Ao referir-se à afirmação do "individualismo qualitativo" no século XIX, Simmel alude à crença em um “indivíduo particular e insubstituível” (1971:222).

$17 \mathrm{O}$ valor imputado à unicidade pode iluminar o horror à clonagem, isto é, à duplicação do M esmo. Essa possibilidade — não muito remota, ao que parece — 
subverte igualmente a lei da reciprocidade e da troca, estabelecendo uma espécie de incesto ao quadrado, ou seja, a do sujeito consigo próprio.

18 Chama a atenção, nas atuais discussões sobre o Prozac (medicamento antidepressivo) nos EUA, o espanto e até mesmo a indignação públicos diante da afirmação de usuários de que, após seu uso, eles teriam se transformado em "outras pessoas".

19 "Free-floating entity" nas palavras do Comitê Warnock e vários outros, ou “organisme libre" (Ladrière 1986:96).

\section{Referências bibliográficas}

AZIZA-SHUSTER, Evelyne. 1988. “Le Traitment 'in Utero': Les Libertés Individuelles en Question". Éthique Médicale et Droits de I'Homme (Série: La Fabrique du Corps Humain). Actes Sud et Inserm: 85-92.

DAWSON, Karen. 1993. "Fertilization and Moral Status: A Scientific Perspective". In: P. Singer et alii (eds.), Embryo Experimentation: Ethical, Legal and Social Issues. Cambridge: Cambridge University Press. pp. 43-52.

DUM ONT, Louis. 1977. “Une Étude Comparative de I'Ideologie M oderne et de la Place en elle de la Pensée Economique". Homo Aequalius. Paris: Gallimard.

FELLOUS, M ichèle. 1991. La Première I mage: Enquête sur l'Échographie Obstétricale. Paris: Nathan.

GALLAGHER, J anet. 1987. “Eggs, Embryos and Fetuses: Anxiety and the Law". In: M. Stanworth (org.), Reproductive Technologies: Gender, Motherhood and Medicine. Cambridge: Polity Press. pp. 139-150.
HARRIS, John. 1990. “Embryos and Hedgehogs: On the M oral Status of the Embryo". In: A. Dyson e J. Harris (orgs.), Experiments on Embryos. London: Routledge. pp. 65-81. . 1993. Wonderwoman and Superman: The Ethics of Human Biotechnology. Oxford: Oxford University Press.

KELLER, Emily Fox. 1995. Refiguring Life: Metaphors of Twentieth-Century Biology. New York: Columbia University Press.

KUHSE, Helga e SINGER, Peter. 1993. "Individuals, Humans and Persons: The Issue of Moral Status". In: P. Singer et alii (eds.), Embryo Experimentation: Ethical, Legal and Social I ssues. Cambridge: Cambridge University Press. pp. 65-75.

LADRIÈRE, Paul. 1986. "Personne Humaine Potentielle et Procréation". Cahiers STS: Ethique et Biologie, 11:95-107.

LUKER, Kristin. 1985. A bortion and the Politics of Motherhood. Berkeley: University of California Press. 
MARTIN, Emily. 1992. The Woman in the Body: A Cultural Analysis of Reproduction. Boston: Beacon Press.

MORGAN, Derek e LEE, Robert G. 1991. Blackstone's Guide to the Human Fertilisation \& Embryology Act 1990. Abortion and Embryo Research: The New Law. London: Blackstone Press Limited.

NATIONAL INSTITUTES OF HEALTH (NIH). 1994. Final Report of the Human Embryo Research Panel. 27 de setembro, datilo.

NOVAES, Simone e SALEM, Tania. 1995. "Recontextualizando o Embrião". Estudos Feministas, 3(1):65-88.

PETCHESKY, Rosalind. 1987. “Foetal Images: The Power of Visual Culture in the Politics of Reproduction". In: M. Stanworth (org.), Reproductive Technologies: Gender, Motherhood and Medicine. Cambridge: Polity Press. pp. 57-80.

PRICE, Frances. 1990. “The M anagement of Uncertainty in Obstetric Practice: Ultrasonography, in Vitro Fertilisation and Embryo Transfer". In: Mc Neil, Varcoe e Yearley (orgs.), The New Reproductive Technologies. New York: St. Martin Press. pp. 123-153.

RAPP, Reyna. 1995. “Hereditary or: Revising the Facts of Life". In: S. Yanagisako e C. Delaney (eds.), Naturalizing Power: Essays in Feminist Cultural Analysis. New York: Routledge. pp. 69-86.

ROBERTSON, J ohn A. 1994. Children of Choice: Freedom and the N ew Reproductive Technologies. Princeton: Princeton University Press.

ROTHMAN, Barbara. 1987. The Tentative Pregnancy: Prenatal Diagnosis and the Future of M otherhood. New York: Penguin Books.

SALEM, Tania. 1992. “A 'Despossessão Subjetiva': Dos Paradoxos do Indi- vidualismo". Revista Brasileira de Ciências Sociais, 7(18):62-77. . 1995. “O Princípio do A nonimato na Inseminação Artificial com Doador Anônimo: Das Tensões entre Natureza e Cultura". Physis: Revista de Saúde Coletiva, 5(1):33-68.

SCHNEIDER, David. 1968. American Kinship: A Cultural Account. New J ersey: Prentice-Hall.

SIM MEL, Georg. 1971. On Individuality and Social Forms (editado por Donald Levine). Chicago: The University of Chicago Press.

STANWORTH, Michelle. 1987.“Reproductive Technologies and the Desconstruction of Motherhood". In: M. Stanworth (org.), Reproductive Technologies: Gender, M otherhood and Medicine. Cambridge: Polity Press.

STRATHERN, Marylin. 1992. Reproducing the Future: Anthropology, Kinship and the New Reproductive Technologies. New York: Routledge. . 1992a. After Nature: English Kinship in the Late Twentieth Century. Cambridge: Cambridge University Press.

WARNOCK, Mary. 1985. A Question of Life: The Warnock Report on Human Fertilisation and Embryology. Oxford: Blackwell. 
Resumo

Dentre os vários dilemas que vêm recentemente emergindo em virtude da afirmação do embrião extracorporal, destaca-se o das condições de permissibilidade para realizar pesquisas com eles. Esta questão vem sendo traduzida nos termos de quais os atributos que conferem ao embrião o caráter de Pessoa e/ou quando se instala nele esta condição. Tomando como material os atuais debates, recomendações e legislações internacionais sobre o tema, o artigo examina as representações de Pessoa aí embutidas. Argumenta-se que o dissenso quanto ao modo de responder ao que é ser Pessoa e/ou seu instante fundador é compensado pela insistência em identificar a Pessoa - no caso, o embrião - como um Indivíduo. Sugere-se, ainda, que o exame desse mesmo material permite também tornar explícitos tensões e paradoxos que se imiscuem na nossa categoria axial de Indivíduo.

\section{Abstract}

A mongst the several dilemmas recently emerging with regard to extracorporeal embryos, the one referring to conditions for allowing research with or on them stands out. The issue is still couched in terms of which attributes are necessary - or at what stage in time - personhood can be conferred on the embryo. Focusing on current debate, international recommendations, and pertinent legislation, the article examines the underlying representations of personhood. The central argument is that the lack of consensus over what it means to be a person (and which qualities instate this condition) in a human being is offset by the insistence on identifying Person - in this case, the embryo - as an Individual. The article further suggests that the review of these documents allows one to display the tensions and paradoxes pervading our central category of Individual. 